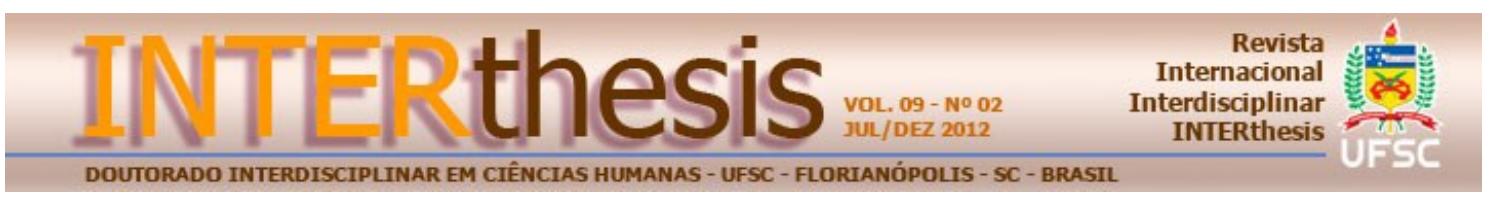

\title{
MERCANTILIZAÇÃO DE ÓRGÃOS HUMANOS PARA TRNASPLANTES INTERVIVOS SOB A ÓTICA DA BIOÉTICA SOCIAL
}

\section{COMMERCIALIZATION OF HUMAN ORGANS FOR TRANSPLANTATION INTERVIVOS UNDER THE PERSPECTIVE OF THE SOCIAL BIOETHICS}

\section{MERCANTILIZACIÓN DE ÓRGONOS HUMANOS PARA TRASPLANTES INTERVIVOS BAJO LA ÓPTICA DE LA BIOÉTICA SOCIAL}

\section{Resumo:}

Fernando Hellmann ${ }^{1}$

Mirelle Finkler ${ }^{2}$

Marta Verdi ${ }^{3}$

A compra e venda de órgãos humanos para transplantes provenientes de doadores vivos vem sendo pauta de discussão mundial no debate bioético, tornando-se um problema de saúde pública. O presente ensaio discute, à luz da Bioética Social, os argumentos utilizados para justificar tais práticas, que giram em torno do bem comum, da pluralidade moral, da autonomia e da liberdade individual. Tais vertentes justificativas assumem caráter liberalista e utilitarista, apresentam possibilidade de duplo standard, não consideram a vulnerabilidade social e ferem a dignidade e os direitos humanos, evidenciando-se uma apologia às leis de mercado. Desta forma, as justificativas para a compra e venda intervivos de órgãos humanos para transplantes acabam por transformar o corpo, ou parte dele, em mercadoria.

Palavras-chave: Ética. Bioética. Transplante. Órgãos. Doadores Vivos.

\section{Abstract:}

Buying and selling human organs for transplants from living donors has been discussed worldwide in the bioethical debate and it is becoming a public health problem. This essay discusses, in light of the Social Bioethics, arguments used to justify such practices, which are related to the common good, moral plurality, autonomy and individual freedom. Such justificatory aspects assume liberal and utilitarian characteristics. They present the possibility of double standard, do not consider social vulnerability, and harm dignity and human rights by evidencing an apology to the market laws. Thus, the justifications for buying and selling human

\footnotetext{
1 Doutorando em Saúde Coletiva pelo Programa de Pós-Graduação em Saúde Coletiva da Universidade Federal de Santa Catarina (UFSC). Coordenador do Curso de Graduação em Naturologia e do Comitê de Ética em Pesquisa da Universidade do Sul de Santa Catarina, Palhoça SC, Brasil. E-mail: fernando.hellmann@unisul.br

${ }^{2}$ Doutora em Odontologia e em Saúde Coletiva. Professora do Departamento de Odontologia e do Programa de Pós-Graduação em Odontologia da Universidade Federal de Santa Catarina, Florianópolis, SC, Brasil. E-mail: mirellefinkler@yahoo.com.br

3 Doutora em Enfermagem. Professora do Programa de Pós-Graduação em Saúde Coletiva Coordenadora do Núcleo de Pesquisa em Bioética e Saúde Coletiva da Universidade Federal de Santa Catarina, Florianópolis, SC, Brasil E-mail: marverdi@hotmail.com
} 
organs for transplantations intervivos eventually turn the body, or part of it, into a commodity.

Keywords: Ethics. Bioethics. Transplantation. Organs. Living Donors.

\section{Resumen:}

La compra y venta de órganos humanos para trasplantes provenientes de donantes vivos viene siendo pauta de discusión mundial en el debate bioético y haciéndose un problema de salud pública. El presente ensayo discute, bajo la luz de la Bioética Social, los argumentos utilizados para justificar tales prácticas, que giran en torno al bien común, de la pluralidad moral, de la autonomía y de la libertad individual. Tales justificaciones asumen carácter liberalista y utilitarista, presentan posibilidad de doble standard, no consideran la vulnerabilidad social y hieren a la dignidad y los derechos humanos, evidenciándose una apología a las leyes de mercado. De esta forma, las justificaciones para la compra y venta intervivos de órganos humanos para trasplantes acaban por transformar el cuerpo, o parte de él, en mercancía.

Palabras-clave: Ética. Bioética. Trasplante. Órganos. Donantes Vivos.

\section{INTRODUÇÃO}

A mercantilização de partes do corpo humano vem sendo pauta de discussão no debate ético mundial, evidenciando um grave problema de saúde pública (BERLINGUER; GARRAFA, 1996; SCHEPER-HUGHES, 2000), principalmente em relação aos transplantes de órgãos. O tema das implicações éticas da compra e venda intervivos de órgãos humanos duplos, como os rins, ou que se regeneram, como o fígado, está relacionado, em especial, às possibilidades decorrentes das inovações científico-tecnológicas na área, em contraponto ao déficit de se conseguir suprimentos (doações de órgãos). Nesse contexto, o comércio de órgãos humanos constitui um grande negócio, conformando um mercado ilegal que toma dimensões concretas e preocupantes no contexto global (BERLINGUER; GAFFARA, 1996).

Uma retrospectiva histórica da ciência biomédica moderna apresenta 0 avanço ocorrido no último século e indica a necessidade de se debater a transação comercial de partes ou de estruturas do corpo humano. llustrativo desta questão é o relato do primeiro transplante de rim, realizado em 1954, que se mostra como um acontecimento significativo para o início dos fatos que culminaram com os extraordinários resultados alcançados no campo da medicina, em relação à sobrevida de um paciente com distúrbios renais (GARRAFA, 1993).

Uma das consequências advindas desses avanços médico-tecnológicos foi a crescente lista de espera para transplantes - filas longas e bastante sensíveis às variações na demanda e na oferta de órgãos - uma vez que tais progressos na área de transplantes vieram acompanhados da dificuldade crescente em se conseguir 
órgãos para todos os procedimentos que poderiam ser realizados. Logo se abriu a discussão do tema da compra e venda de partes específicas do corpo em vida (GARRAFA, 1993; MARINHO, 2006).

No Brasil, a legislação é apontada como falha no que se refere à utilização de rins para transplantes a partir de doadores vivos não parentes, permitindo brechas para o comércio ilegal de órgãos no país (PASSARINHO; GONÇALVES; GARRAFA, 2003). Frente a isso, propostas para a legalização da compra e venda de órgãos humanos para transplante intervivos são encontradas no debate bioético ainda no plano jurídico e filosófico. Isso ocorre não apenas no Brasil (STANCIOLI et al., 2011) e na Inglaterra (HARRIS, 2002), mas em várias outras partes do mundo (BERLINGUER; GAFFARA, 1996; SCHEPER-HUGHES, 2000), gerando a urgente necessidade de se debater se a compra e venda de órgãos humanos pode ser eticamente aceitável de alguma maneira.

Berlinguer (1993) cunhou o termo "Bioética Justificativa" para designar a corrente da Bioética permeada por tendências utilitaristas, contratualistas e, às vezes, baseadas na teoria dos direitos, como uma corrente que defende o comércio de partes do corpo, chegando até a criar expressões verbais que legitimam o mercado de órgãos, tornando-o algo mais "leve" e moralmente válido. Nesse neologismo, a venda passa a ser chamada de rewarded gifting (doação remunerada) e o vendedor rewarded donor (doador remunerado). Para além das novas denominações, esse ato comercial ainda seria considerado um ato de altruísmo indireto, ao permitir um mercado humano mais digno entre doadores vivos que vendem órgãos específicos a compradores com os quais não possuem relação de parentesco.

Diante desta problemática, o presente ensaio tem como objetivo discutir, à luz da Bioética Social, argumentos encontrados na literatura especializada em bioética utilizados para justificar a mercantilização de órgãos para transplantes intervivos, entre os quais: a justificativa da necessidade para o bem comum, o argumento da pluralidade moral, e do respeito à autonomia e à liberdade individual de dispor do próprio corpo. Ao final, buscou-se realizar algumas ponderações acerca da proposta de um modelo monopsônico que vem sendo apresentado como estratégia para um "mercado ético" do corpo humano.

Cabe antes, no entanto, esclarecer que por Bioética Social se entende um conjunto de referenciais de análise em bioética que propõe um olhar crítico e R. Inter. Interdisc. INTERthesis, Florianópolis, v.9, n.2, p.123-138, Jul./Dez. 2012 
libertário - especialmente proveniente das contribuições do campo da Saúde Coletiva à Bioética - aos conflitos éticos da vida humana no âmbito privado e público, na individualidade e coletividade (HELLMANN; VERDI, 2012). Dentre os seus referenciais destacam-se a Bioética Cotidiana (BERLINGUER, 2004), a Bioética de Intervenção (PORTO; GARRAFA, 2005) e a Bioética de Proteção (SCHRAMM, 2003).

\section{JUSTIFICATIVAS PARA O BEM COMUM}

O bem comum configura-se como a finalidade ou o objetivo a ser conquistado pela sociedade. As alegações de que a venda de órgãos tais como os rins e parte do fígado são em prol do bem comum giram em torno: 1 - da expectativa de diminuição da fila de espera para a realização de transplantes, 2 - da redução no número de problemas advindos de transplantes clandestinos, 3 - de que transplantes a partir de doadores vivos tem maior sucesso, 4 - da diminuição dos custos envolvidos nos tratamentos dos pacientes que aguardam transplantes (como, por exemplo, a hemodiálise), e 5 - do argumento de que a não liberação do comércio de órgãos humanos tolhe o desenvolvimento científico.

Assim, uma das justificativas no arsenal defensor da comercialização de órgãos é de que o incentivo financeiro para doação, através de um processo legalizado, poderia prover rins e outros órgãos, aumentando o número de transplantes, e consequentemente, diminuindo a mortalidade na lista de espera (GARRAFA, 1993). Desta forma, consideram-se apenas os receptores dos órgãos, deixando os "doadores" esquecidos no equacionamento desse problema ético. Além disso, alegar que a compra e venda de órgãos aumentariam o número de transplantes e diminuiriam a mortalidade na lista de espera é, em algumas situações, como nos casos de países em desenvolvimento, uma afirmativa que se torna frágil, porque, ao mesmo tempo em que se sacrificaria a saúde das pessoas mais pobres para salvar as vidas de algumas pessoas mais ricas que teriam condições de pagar pela compra, deixar-se-ia de se incluir na discussão ética relacionada aos transplantes as altas taxas de mortalidade nesses países que poderiam ser combatidas com medidas básicas de atenção primária.

O fato é que transplantes em clínicas clandestinas ocorrem, inclusive com pessoas buscando outros países para realizar a cirurgia, o que frequentemente gera 
intercorrências pela clandestinidade dos procedimentos envolvidos (KENNEDY et al., 2005; MCDONALD; RUSS, 2002). Esses fatos também são tomados como argumento de defesa do mercado de órgãos, justificando-se que, caso legalizado, tais intercorrências seriam minimizadas (STANCIOLI et al., 2011). Contudo, há que se considerar que, novamente, apenas o lado do receptor é pesado nessa argumentação, pois quem doa ou vende um rim pode ter sua expectativa de vida diminuída.

No caso dos transplantes renais, tecnicamente falando, são preferíveis doadores vivos a doadores falecidos, pois o tempo de vida do receptor tende a aumentar. Além disso, sabe-se que o transplante renal tem vantagens significativas para a sobrevida e para a qualidade de vida dos pacientes transplantados em relação ao tratamento de diálise (MCDONALD; RUSS, 2002). Tais fatos colaboram com a defesa da comercialização de órgãos, mas desconsideram que a sobrevida e a melhor qualidade de vida de uns não necessariamente justificam eticamente a diminuição da expectativa de vida de outros, no caso, dos vendedores de órgãos, geralmente pessoas socialmente vulneráveis.

As justificativas em nome do bem comum também giram em torno dos altos custos das terapias alternativas aos transplantes, como as diálises, que chegam perto de $10 \%$ dos orçamentos dos serviços de saúde em países como o Japão e os Estados Unidos (MCDONALD; RUSS, 2002). Justificar a necessidade da mercantilização de órgãos para reduzir os custos orçamentários, em última análise, reduz a saúde humana a um valor monetário. Vale lembrar que garantir vantagens à economia era um dos mais populares argumentos sobre a importância da escravidão. O bem comum, necessário ao desenvolvimento econômico, era ainda considerado um ato de compaixão aos servos, do qual também se beneficiariam. No caso em pauta, os "novos escravos" ganhariam dinheiro e não morreriam de fome. Berlinguer (2004), ao criticar essa questão, ilustra a arguição do bem comum ao vendedor e ao receptor, através das palavras de um cirurgião que afirmou: "se um pobre indiano morrendo de fome vende um rim para salvar a vida de um rico Xeique Árabe que está morrendo de uremia, fazem-se duas pessoas felizes" (BERLINGUER, 2004, p.193).

O bem comum é usado ainda como argumento no mercado biotecnológico no sentido de que o conhecimento científico ficaria contido se os transplantes fossem 
tolhidos ao não se permitir a remuneração de órgãos de "doadores" vivos. Contudo, o avanço científico não é justificativa eticamente plausível:

[...] até que ponto o mercado humano pode ter sido e ser um fator não de crescimento, mas de estagnação e regressão, ou seja, um obstáculo ao desenvolvimento técnico-científico e social? [...] é correto, por impulsos causados por exigências momentâneas, renunciar aos valores históricos e morais que são os componentes essenciais da nossa sociedade? (BERLINGUER, 2004, p.87).

Pensa-se no mercado humano como justificativa do bem comum como via única de diminuição da diferença entre a demanda e a oferta. Cunham-se até expressões como "comprar ou morrer" como forma de afirmar não haver alternativa. Para sobreviver seria necessário comprar ou vender (GARRAFA, 1993; BERLINGUER, 2004). Porém, o bem comum só é possível quando se tem uma sociedade justa e equitativa. Nem o desenvolvimento científico, nem os custos orçamentários, tampouco os problemas advindos de transplantes clandestinos ou a necessidade de se diminuir as filas para transplantes justificam eticamente um ato que fere a dignidade e os direitos humanos como é o da comercialização de órgãos humanos.

\section{DA PLURALIDADE MORAL}

Dentre as justificativas para a mercantilização de órgãos humanos para transplante, encontra-se a da dificuldade de haver padrões éticos globais. O exemplo do altruísmo, como valor moral diferentemente apreciado nas distintas sociedades, é tomado como justificativa para um possível mercado de órgãos humanos vivos. Também a influência da moralidade judaico-cristã na sociedade ocidental é apontada como fator que dificulta o debate bioético laico sobre o assunto.

Cameron e Hoffenberg (1999) afirmam que não há imperativos morais absolutos que proibiriam a venda de rins, desde que se cuide para que não ocorram abusos, uma vez que é difícil encontrar padrões éticos globais. Os autores abordam o pagamento financeiro pela "doação" de órgãos na perspectiva de que o assunto deve ser analisado de forma a levar em consideração as diferentes sociedades e seus distintos códigos morais. Do mesmo modo, Mansell (2004) aponta a 
diversidade cultural e moral como dificuldade para uma ética universal, sendo tal fato uma possível justificativa para o estabelecimento das "doações remuneradas", tal como são denominadas em certos países, segundo o autor.

Ainda que um padrão moral global pudesse ser encontrado, considerar as diferentes sociedades e seus distintos códigos morais, sem levar em conta a assimetria entre os grupos sociais, levaria a conclusões relativistas e à legitimação de "duplo standard": uma ética para países desenvolvidos e outra para os países em desenvolvimento, tal como vem acontecendo na pesquisa biomédica (GARRAFA; LORENZO, 2010). Frente às possibilidades de "duplo standard", a Declaração Universal de Bioética e Direitos Humanos se mostra como um marco bioético para o balizamento de questões no âmbito clínico e social, possível de ser aplicada em situações como a aqui em análise. Tal declaração apresenta potencialidades de caráter global, uma vez que foi adotada por aclamação dos 191 Estados-membros da UNESCO (2005), em sua 33 ${ }^{\text {a }}$ Conferência Geral, em 19 de outubro de 2005, na cidade de Paris. Em seus princípios fica evidente que a mercantilização de órgãos humanos dificilmente seria justificada.

A pluralidade moral está implicada no debate, apelando-se para as diferentes práticas culturais acerca de alguns valores como o altruísmo. $O$ apelo por doações puramente altruístas é contestado pelos defensores do comércio de órgãos mediante observações de experiências relativas ao comércio de outras estruturas do corpo humano. Por exemplo, nos Estados Unidos, país onde as relações comerciais e contratualistas dominam o pensamento nas mais diversas áreas, o caráter altruísta da doação de sangue não foi um fator suficiente para suprir suas demandas, questão resolvida com a retribuição financeira pelas "doações" (CAMERON; HOFFENBERG, 1999). Contudo, ainda que os valores do altruísmo e da solidariedade sejam menos vivenciados em algumas sociedades que em outras, não seria fato capaz de justificar eticamente a comercialização de órgãos humanos, pois, dessa forma, novamente os benefícios seriam dirigidos aos necessitados da fila de espera em detrimento dos possíveis vendedores que, usualmente, estão em situação de vulnerabilidade social.

Ainda acerca da pluralidade moral, Mansell (2004) aponta a globalização da medicina como fator facilitador da incorporação de conceitos baseados na moralidade judaico-cristã aos valores da ética médica. Com isso, reforçar-se-ia o contexto global da proibição do comércio de órgãos, em especial no caso de 
doadores de rins em vida. Stancioli et al. (2011) também afirmam que o tema da mercantilização de órgãos humanos provenientes de doadores vivos é contaminado pelo discurso da sacralidade do corpo, o que dificulta o debate laico sobre o assunto.

Sob a ótica da Bioética Social, a sacralidade do corpo não é argumento para a proibição da compra e venda de órgãos humanos. A despeito disso, tem-se grande debate acerca do aborto, que ao contrário das visões personalistas e naturalistas que recorrem à sacralidade da vida, condenando de antemão o abortamento nos mais variados casos, a Bioética Social tem se mostrado a favor dessa prática em certas circunstâncias (BERLINGUER, 2004). Portanto, o argumento da necessidade de um ponto de vista laico para o debate não se sustenta para justificar o mercado de órgãos, visto que a Bioética Social tem como premissa ser laica, zelando para que o Estado, o qual é responsável pelas políticas públicas, também o seja de fato.

Como visto, a pluralidade moral é um fato real e deve ser considerada no debate bioético. Contudo, a proposta do mercado de órgãos humanos não pode ser justificada pela dificuldade de padrões éticos globais sob pena de se criar um "duplo standard", valorando a vida de uns em detrimento de outros.

\section{DO RESPEITO À AUTONOMIA E À LIBERDADE INDIVIDUAL}

Autores que amparam moralmente a mercantilização de órgãos humanos duplos ou que se regeneram (ENGELHARDT, 1998; CAMERON; HOFFENBERG, 1999; STANCIOLI et al., 2011) pautam-se, sobretudo, pelo princípio da autonomia e, portanto, do valor da liberdade individual. Tal argumento é amplamente debatido nos mais diversos referenciais bioéticos e defendido naqueles provenientes de correntes de inspiração liberalista, podendo, no entanto, ser ressignificado à luz da Bioética Social.

Um dos maiores expoentes da Bioética norte-americana, Hugo Tristam Engelhardt Jr., sustenta que o corpo de uma pessoa, bem como seus talentos e suas habilidades, são primordialmente dela, podendo, portanto, pela autonomia de suas decisões, dispor de tais propriedades/características (ENGELHARDT, 1998, p. 197). Essa visão filosófica anglo-americana assume uma vertente utilitarista, ou seja, avalia os resultados da ação para considerar seu estatuto moral. Assume também a tradição do liberalismo, inspirado na defesa dos direitos e da propriedade privada, 
centrando-se na autonomia do indivíduo e inclinando-se à tecnicalização ou funcionalização da Bioética (NEVES, 1996).

O discurso liberalista não repousa apenas em sociedades como a estadunidense. No panorama brasileiro, por exemplo, essa tendência também é observada no panorama das transações de órgãos para transplante. Sobre isso, Stancioli et al. (2011) sustentam que o exercício da autonomia começa no próprio corpo e, portanto, quanto maior é a possibilidade de se usufruir e dispor do corpo, maiores são as chances de as pessoas realizarem seus sonhos e projetos de vida. Assim, para os autores, a visão liberalista da autonomia transcenderia a noção de intangibilidade do corpo humano, possibilitando justificar a mercantilização de órgãos humanos.

Em nome da autonomia, a venda da força de trabalho por um salário e a prostituição como forma de dispor do próprio corpo são citados como analogias para justificar a comercialização das funções e das partes corporais (BERLINGUER, 2004). Um exemplo pode ser visto nas palavras de Savulescu (2003, p. 139): "As pessoas têm o direito de tomar a decisão de vender uma parte do corpo. Se nós permitimos a venda do nosso trabalho, por que não vender os meios para realizar esse trabalho?".

A comparação da venda do esforço de trabalho do corpo ou mesmo da prostituição em relação ao mercado de órgãos humanos podem ser contraargumentados pela provisoriedade e reversibilidade dessas situações em relação à irreversibilidade e permanência da doação altruísta ou da venda de um órgão (BERLINGUER, 2004), que podem trazer prejuízos relacionados à capacidade funcional e riscos à saúde, potencialmente ainda mais graves quando extraídos de pessoas em condições de vulnerabilidade social.

Há, portanto, quem se utilize do princípio da autonomia para justificar o mercado de órgãos, mas há também quem alegue que tal argumento não se aplica nem para justificar, tampouco para condenar tal transação. Diniz (2001) chama atenção para o fato de que o apelo ao princípio da autonomia é sem sentido no contexto da comercialização de órgãos de doadores vivos, seja para justificar a eticidade ou mesmo a imoralidade da comercialização.

O fato é que a mulher indiana que vende seu rim por dois ou três mil dólares, um montante de dinheiro incalculável para os padrões locais de uma plantadora de chá, onde o salário mensal é de vinte dólares, 
definitivamente não é heterônoma. No caso dessa mulher, a decisão pela venda de um rim foi fruto de um cálculo de forças, onde de um lado estava ser provedora do prazer britânico pelo chá importado dos campos indianos e de outro um futuro de reduzida sobrevida, com ou sem um rim. Nesse cálculo de possibilidades e ofertas, por mais doloroso que possa parecer, a decisão dessa mulher é completamente autônoma. A estrutura de opressão se mantém: a novidade é que, além da falta do rim, essa mulher não precisa trabalhar como antes nas plantações de chá (DINIZ, 2001, p. 218).

Já para a Bioética Social, consentir com a retirada de um rim por recompensa financeira é colocar em questionamento o próprio caráter autônomo dessa decisão, uma vez que se entende que para exercer autonomia é preciso ter supridas as necessidades básicas humanas para se viver com dignidade. No exemplo acima, a indiana está no espaço da necessidade e não no da liberdade, ou seja, encontra-se em estado de vulneração. Sua escolha de vender um rim, portanto, não é autônoma, pois, muito provavelmente, se não vivesse em estado de vulneração, não "optaria" pela venda de um dos seus rins. $O$ argumento da autonomia, portanto, não cabe "[...] em situações onde prevalecem a marginalização, a pobreza, o desamparo social e a omissão do Estado [...]" (SCHRAMM; ANJOS; ZOBOLI, 2007, p. 31).

O princípio da autonomia, que garantiria ao doador o direito de usar seu corpo como desejar, deve também ser compreendido como um fator que possibilitaria a exploração dos desfavorecidos. Mesmo que tal princípio pudesse se aplicado apenas em situações nas quais populações e indivíduos tivessem capacidades e condições sensivelmente semelhantes (SCHRAMM; ANJOS; ZOBOLI, 2007), provavelmente a venda de órgãos seria realizada pelas pessoas de mais baixa renda e instrução, não obstante imigrantes.

A compreensão da vulnerabilidade humana transcende o princípio do respeito à autonomia, pois expressa a preocupação pela fragilidade dos seres humanos, seja nos aspectos da vulnerabilidade biológica ou corporal, social ou mesmo cultural. A vulnerabilidade social, que consiste na fragilidade dos seres humanos para vivenciar sua própria vida de forma coerente e ter benefícios compartilhados na sociedade de forma igualitária, favorece que as pessoas mais pobres decidam sujeitar-se mais facilmente à venda de um dos seus órgãos. Ou seria considerado normal que alguma pessoa rica colocasse um rim à venda?

Uma das diferenças substanciais entre as tendências bioéticas que justificam a mercantilização de partes do corpo humano para transplantes intervivos e a Bioética Social, é que as primeiras priorizam a autonomia da pessoa sob o ponto de 
vista liberalista, ao passo que a última contextualiza a autonomia individual numa conjuntura social, ponderando tal princípio com a vulnerabilidade e considerando o todo - a sociedade - em primazia sobre as partes - o indivíduo.

Perante as considerações liberalistas sobre o mercado humano existe o preceito da dignidade humana, para a qual o homem não tem preço, é sempre sujeito, não objeto. É fim em si mesmo e não um meio. Para a Bioética Social, requer-se uma metafísica para a dignidade humana que considere que, à parte do corpo biológico, existe um corpo social onde cada indivíduo é visto em um conjunto mais amplo e contextualizado. Uma metafísica para a dignidade humana que implique no tratamento com respeito a todos os seres humanos e a seus direitos.

\section{MONOPSÔNIO: PROPOSTA ÉTICA PARA UM MERCADO DE ÓRGÃOS?}

Ainda que para a Bioética Social não fosse possível a implementação de qualquer sistema de mercantilização dos órgãos duplos ou que se regeneram, cabe relatar uma das propostas existentes na literatura para esse tipo de comércio. Um dos atuais propositores desse tipo de compra e venda, o inglês John Harris (2002), descreve uma defesa ética para o mercado de órgãos, propondo a criação de um tipo de comercialização que ele designa monopsônio - um mercado onde haveria apenas um adquirente e que na Grã-Bretanha poderia ser gerido, como estrutura mais idônea, pelo National Health Service (NHS).

Harris (2002) defende que tal mercado poderia ser administrado de acordo com princípios éticos. Ao estabelecer um monopsônio, em que somente um comprador existisse para todos os vendedores, não haveria "diferença de preços" e, além dessa regulação, tal projeto seria responsável por assegurar a distribuição com equidade a todos que necessitassem de transplantes. Isso impediria que os mais ricos usassem seu poder de compra para explorar o mercado às custas dos mais pobres. Incentivos fiscais também entrariam na forma de pagamento. Essa venda, segundo o autor, teria características de vantagens financeiras ao vendedor, caráter altruísta e ainda o fator de contribuir para o bem público.

Tal proposta, baseada na justiça e na autonomia, considerando-se as características culturais para onde seria aplicada, pode parecer razoável. No entanto, a legalização do mercado humano em um país específico, mesmo que feito segundo um monopsônio, representaria um risco no sentido de outros países, em 
condições sociais, econômicas e culturais bastante diversas da Grã-Bretanha, tomarem-no como modelo, fomentando, por exemplo, o turismo de transplantes.

Cabe aqui lembrar, a título de ilustração, do filme britânico "Coisas belas e sujas" (Dirty Pretty Things), de 2003, dirigido por Stephen Frears, no qual o personagem principal, um nigeriano que trabalhava em Londres como recepcionista em um pequeno hotel, descobre o tráfico ilegal de órgãos, sem no entanto poder denunciá-lo por estar ilegalmente no país. Dentre as transações ilícitas apresentadas na trama, destaca-se a confecção de passaportes falsos para imigrantes ilegais que cederem um dos seus rins.

É ainda preciso mencionar as possíveis e perigosas consequências da legalização do mercado de órgãos humanos, entre as quais: injustiça no sistema de captação de órgãos (pobres e imigrantes seriam vendedores majoritariamente), fortalecimento do tráfico de órgãos em clínicas particulares, prejudicando os programas nacionais de transplantes e diminuindo a confiança na justiça pública, diminuição no estímulo para o desenvolvimento de programas de transplantes a partir de doadores falecidos, bem como nos comportamentos altruístas e solidários.

\section{CONSIDERAÇÕES FINAIS}

Os constantes avanços da biotecnologia surgem com grandes benefícios, mas também com dramáticas implicações, não raramente concentrando-se em pesquisas que promovem avanços para suprir necessidades de países centrais em detrimento dos periféricos, e facilitando o surgimento de um mercado lucrativo dentro da lógica individualista neoliberal. Junto com os avanços científicos, no caso específico de transplantes de órgãos, emerge a possibilidade de transformar órgãos humanos em mercadorias, revelando evidências de um discurso bioético justificativo envolto pelas leis do mercado. Nesse contexto, o interesse mercantilista passa a prevalecer sobre o interesse moral da coletividade, acabando por subverter os valores da ciência e da ética. Frente ao fato, a Bioética Social, que visa descrever e apresentar soluções frente às formas de dominação que vem ocorrendo no campo das ciências e da vida, procura driblar o relativismo ético que pauta as discussões acerca do tema.

O reducionismo que prevalece em algumas correntes bioéticas conduziu a esse relativismo ético que fala a favor da comercialização de órgãos através do 
argumento para o bem comum. Contudo, nem as grandes filas para transplantes, nem os altos custos orçamentários, nem tampouco a necessidade do progresso científico podem sobrepor a dignidade e os direitos humanos. Ainda sob o argumento do pluralismo moral, propõem-se estabelecer leis específicas, baseandose na autonomia em detrimento da vulnerabilidade humana e da justiça social.

Defronte tal argumento, deve-se reconhecer que a lógica de mercado pode interferir no contexto filosófico, levando a crer que os fins justificam os meios. Essa lógica tende a legitimar a preponderância dos ricos sobre os pobres, ou dos países centrais sobre os periféricos. Evidencia-se então a lógica do duplo standard, que emerge com o potencial de se criar um padrão ético para países ricos e outro para países pobres, valorando a vida de uns em detrimento da vida dos outros. A diversidade cultural e a pluralidade moral existem. Portanto, faz-se necessária a construção de mecanismos mediadores das disparidades morais com a finalidade de se obter um consenso ético global, inclinado à equidade e não às leis do mercado.

Os argumentos da autonomia e da liberdade individual lançados no debate em pauta passaram a ser aplicados de forma destorcida ao se desconsiderar a vulnerabilidade humana. Assim, o apelo ao princípio da autonomia acaba prevalecendo sobre o da justiça social, tornando a possibilidade de um mercado de órgãos humanos uma forma a mais de existência injusta e desigual.

Quanto a uma possível comercialização ética de órgãos duplos ou que se regeneram, tal como se propõe no modelo monopsônico, vale ainda comentar seu efeito perverso de redução da solidariedade ao ampliar o sentimento de não ser necessário se preocupar com o outro, uma vez que haveria uma reparação financeira pelo dano causado pela venda do órgão.

A fim de cuidar para que não se perca a responsabilidade social sobre a saúde coletiva, a Bioética Social se posiciona contrariamente à transformação das pessoas ou de parte dos seus corpos em mercadorias, pois esse ato parece desconsiderar que o homem não tem preço, que é sempre sujeito e não objeto. Que é fim em si mesmo e não um meio. O corpo humano deveria ser compreendido como res extra commercium. Esse entendimento faria com que o corpo social fosse protegido em sua vulnerabilidade e ganhasse habeas corpus frente às leis de mercado, concretizando uma forma de zelar pelos mais desamparados socialmente, uma vez que a dignidade e os direitos humanos não podem estar à mercê das necessidades científico-tecnológicas e de consumo. 


\section{REFERÊNCIAS}

BERLINGUER, G.; GARRAFA, V. O mercado humano - Estudo bioético da compra e venda de partes do corpo. Brasília: UnB, 1996.

Bioética cotidiana. Brasília: UnB, 2004.

. Corpo humano: mercadoria ou valor? Rev. Estudos Avançados, São

Paulo, v.7, n.19, p.167-92, 1993. Disponível em: <http://www.scielo.br/pdf/ea/v7n19/05.pdf>. Acesso em: 23 set. 2012.

CAMERON, J.S.; HOFFENBERG, R. The ethics of organ transplantation reconsidered: paid organ donation and the use of executed prisoners as donors. Kidney Int., v.55, n.2, p.724-32, Feb., 1999. Disponível em: <http://www.ingentaconnect.com/content/bsc/kid/1999/00000055/00000002/art000>. Acesso em: 23 set. 2012.

DINIZ, Debora. As fronteiras da pesquisa antropológica: Ética, Autonomia e Tráfico de Órgãos. Um comentário a The Global Traffic in Human Organs, de Nancy Scheper-Hughes. Cad. Saúde Pública, Rio de Janeiro, v. 17, n. 1, feb. 2001. Disponível em: <http://www.scielo.br/scielo.php?script=sci_arttext\&pid=S0102311X2001000100022\&lng=en\&nrm=iso>. Acesso em: 26 set. 2012. http://dx.doi.org/10.1590/S0102-311X2001000100022.

ENGELHARDT JR, H.T. Fundamentos da bioética. São Paulo: Loyola, 1998. 518 p.

GARRAFA, V. O Mercado de Estruturas Humanas. Bioética, v.1, n.1, p.115-23, 1993. Disponível em: <http://revistabioetica.cfm.org.br/index.php/revista bioetica/article/view/490/307>. Acesso em: 23 set. 2012.

; LORENZO, C. Helsinque 2008: redução de proteção e maximização de interesses privados. In: CAPONI, S. et al. (Org.). Medicalização da vida: ética, saúde pública e indústria farmacêutica. Palhoça: Unisul, 2010. p. 21-35.

HARRIS, J. An ethically defensible market in organs. BMJ, v.325, n.7356, p.114-5, Jul. 2002. Disponível em: <http://www.ncbi.nlm.nih.gov/pmc/articles/PMC1123654/>. Acesso em: 23 set. 2012. 
HELLMANN, F.; VERDI, M. Bioética Social: reflexões sobre referenciais para a saúde coletiva. In: HELLMANN, F.; VERDI, M.; GABRIELLI, R.; CAPONI, S. Bioética e Saúde Coletiva: perspectivas e desafios contemporâneos. Florianópolis: DIOESC, 2012.

KENNEDY, S.E. et al. Outcome of overseas commercial kidney transplantation: an Australian perspective. Med J Aust, v.182, n.5, p.224-7, 2005. Disponível em: <https://www.mja.com.au/journal/2005/182/5/outcome-overseas-commercial-kidneytransplantation-australian-perspective>. Acesso em: 23 set. 2012.

MANSELL, M.A. The ethics of rewarded kidney donation. Middlesex Hospital, London, UK. BJU Int., v.93, n.9, p.1173-4, Jun. 2004. Disponível em: $<$ http://www.blackwell-

ynergy.com/doi/pdf/10.1111/j.1464410X.2004.04891.x?cookieSet=1>. Acesso em: 23 set. 2012

MARINHO, A. Um estudo sobre as filas para transplantes no Sistema Único de Saúde brasileiro. Cad. Saúde Pública, Rio de Janeiro, v. 22, n. 10, p.2229-39, 2006. Disponível em: <//www.scielo.br/scielo.php?script=sci_arttext\&pid=S0102311X2006001000029\&lng=en\&nrm=iso>. Acesso em: 23 set. 2012.

MCDONALD, S.P.; RUSS, G.R. Survival of recipients of cadaveric kidney transplants compared with those receiving dialysis treatment in Australia and New Zealand 1991-2001. J Am Soc Nephrol, v.12, p.589-97, 2002. Disponível em: <http://jasn.asnjournals.org/content/12/3/589.full.pdf>. Acesso em: 23 set. 2012.

NEVES, M. C. P. A Fundamentação Antropológica da Bioética. Bioética. no. 4. 1996. p. 07-16. Disponível em: <http://revistabioetica.cfm.org.br/index.php/revista_bioetica/article/viewArticle/392>. Acesso em: 23 set. 2012.

PASSARINHO, L.E.V.; GONCALVES, M.P.; GARRAFA, V. Estudo bioético dos transplantes renais com doadores vivos não-parentes no Brasil: a ineficácia da legislação no impedimento do comércio de órgãos. Rev. Assoc. Med. Bras., São Paulo, v. 49, n. 4, p.382-8, 2003. Disponível em: $<$ http://www.scielo.br/scielo.php?script=sci_arttext\&pid=S010442302003000400028\&Ing=en\&nrm=iso>. Ācesso em: 23 set. 2012.

PORTO, D.; GARRAFA, V. Bioética de Intervenção: considerações sobre a economia de mercado. Revista Bioética, Brasília - DF, v. 13, n.1, p. 111-23, 2005.

SAVULESCU, J. Is the sale of body parts wrong? BMJ, v.29, n.3, p. 138-9, 2003. 
Disponível em: <http://www.ncbi.nlm.nih.gov/pmc/articles/PMC1733718/>. Acesso em: 23 set. 2012.

SCHEPER-HUGHES, N. The Global Traffic in Human Organs. Current Anthropology, v.41, n.2, April, 2000. Disponível em: <http://escholarship.org/uc/item/0fm776vf>. Acesso em: 23 set. 2012.

SCHRAMM, F. R. A bioética da proteção em saúde pública. In: FORTES, P.A.C., ZOBOLI, E.L.P. Bioética e Saúde Pública. São Paulo: Centro Universitário São Camilo/ Loyola, 2003.

ANJOS, M.F.; ZOBOLI, E. A questão das tendências epistemológicas ou de fundamentação. In: ANJOS, M.F.; SIQUEIRA, J.E (Orgs). Bioética no Brasil: tendências e perspectivas. Aparecida: Idéias \& Letras; São Paulo: Sociedade Brasileira de Bioética, 2007.

STANCIOLI, B. et al. Sistema nacional de transplantes: saúde e autonomia em discussão. Rev. Direito Sanit., São Paulo, v. 11, n. 3, fev. 2011. Disponível em: <http://www.revistasusp.sibi.usp.br/scielo.php?script=sci_arttext\&pid=S151641792011000100007\&Ing=pt\&nrm=iso>. Acesso em: 23 set. 2012.

UNESCO. Organização das Nações Unidas para a Educação, Ciência e Cultura. Declaração Universal sobre Bioética e Direitos Humanos. 2005. Disponível em: $<$ http://bvsms.saude.gov.br/bvs/publicacoes/declaracao_univ_bioetica_dir_hum.pdf>. Acesso em: 23 set. 2012.

Dossiê:

Recebido em: Setembro/2012

Aceito em: Novembro/2012 